\title{
Geomagnetic Investigations in the Seismoactive Regions of Middle Asia
}

\author{
V.A. Shapiro, ${ }^{*}$ A.N. Pushkov, ${ }^{* *}$ K.N. Abdullabekov, ${ }^{* * *}$ \\ E.B. Berdaliev, ${ }^{* * *}$ and M.Yu. Muminov*** \\ *Institute of Geophysics, Academy of Sciences, Sverdlovsk, U.S.S.R. \\ **Institute of Earth Magnetism, Ionosphere and Radio Wave Propagation, \\ Academy of Sciences, Moscow, U.S.S.R. \\ ***Institute of Seismology, Uzbek Academy of Sciences, Tashkent, U.S.S.R.
}

(Received September 1, 1977)

\begin{abstract}
Investigations of local geomagnetic nield changes have been carried out in Middle Asia in the following regions: Tashkent, including Charvak reservoir, Fergana and Kyzyl-Kum. Since 1968, a variety of total field features have been observed there, including: (a) slow changes at separate stations, which may be explainable by compression or tension of individual earth's crustal blocks; (b) a variety of field changes with amplitudes of a few gammas and periods of 0.5-2 years; (c) variations, which may be due to different conductivity of rocks; (d) anomalous changes in the fracture zones; (e) anomalous variations in the Charvak region, connected with reservoir filling. The amplitudes of these variations are 3-5 nT/year at Fergana, 8-9 nT/year at Kyzyl-Kum, 20-25 nT/year at Tashkent regions and up to 15-25 nT/year at Charvak reservoir area. Sometimes these anomalous changes are correlated with seismic activity (for example, Tashkent 1968 earthquakes).
\end{abstract}

\section{Introduction}

At the present time, investigations of secular variation anomalies of the geomagnetic field in the Middle Asia are underway in the geodynamical polygons of Tashkent, Fergana and Kyzyl-Kum, and in the area of the water reservoir of Charvak (Fig. 1). Those polygons are situated in the areas of different seismotectonic conditions. Fergana polygon is in an active orogenic area of the Central Tyan-Shan. Kyzyl-Kum polygon is situated within a platform, characterized by intensive recent fracturing. The Tashkent polygon is in a transition zone between the orogene and platform. Geomagnetic field variations, caused by the natural processes in the earth's crust were observed at all the polygons. In the area of the water reservoir of Charvak geomagnetic field total force secular variations, induced by changeing pressures in the reservoir, have been studicd.

\section{Tashkent Polygon}

Geomagnetic studies in the Tashkent polygon were started in 1968. Measurements were made with proton precession magnetometers by the method of repeated 


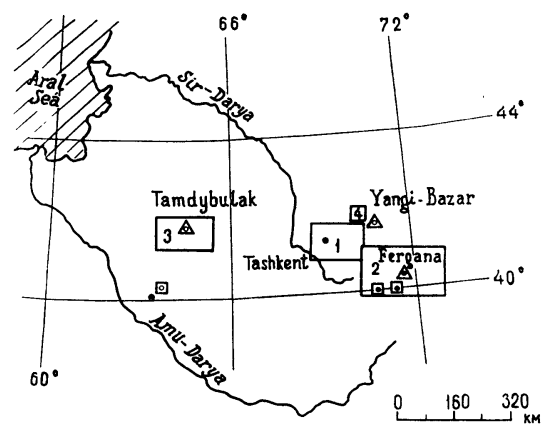

Fig. 1. Sketch map of Middle Asian geomagnetic polygons.

route surveys. The distance between observations points was $4-5 \mathrm{~km}$ at the polygon and $1-2 \mathrm{~km}$ in the region of the water reservoir. Measurements in the Tashkent polygon were made on three routes, lying along the rupture zone and a series of faults (Abdullabekov and Maksudov, 1975). The frequency of the measurements was 3-4 cycles a year. The mean square error of measurements was $\pm 2 \mathrm{nT}$. Observations were related to the total force field $T$ of the Yangi-Bazar magnetic observatory. The distance from the magnetic observatory to the measurement points does not exceed $70 \mathrm{~km}$. In 1971-1972 anomalous changes of the geomagnetic field total force with 20-25 nT intensity were observed on a route lying along the zone of rupture. These changes appear to be associated with an earthquake of magnitude $M=4-4.5$ which took place near the route. The following year measurements on the routes were continued. However, anomalous changes of the field, exceeding by a factor of 3 the mean square error, were not seen. This is consistent with the seismological data as there were no earthquakes with magnitude $M$ over 2.5 near the observation points during 1973-1977.

\section{Kyzyl-Kum Polygon}

Measurements in the Kyzyl-Kum polygon were made at the network of the points established in 1974 (Fig. 2). Measurements of total field were made synchronously at the points of reference. The repetition frequency was one cycle a year. Measurements during the cycles were repeated at every point twice in different phases of daily variations of total force. The distance between the reference and the observation points does not exceed $80 \mathrm{~km}$. Routes cross active faults and sections with intense fracturing and different structural blocks. The anomaly of the stationary field at the routes reached some hundred nano Teslas. The depth of the Paleozoic basement is $0-500 \mathrm{~m}$. Measurements at the points were made in 1974-1975 with a proton magnetometer IIM-5, in 1976-1977 with proton magnetometers G-816 of the 'Geometrics' firm and T-MII of the Institute of Geophysics, Urals Scientific Center, USSR Academy of Sciences (MAKSIMOVSKIKH and SHAPIRO, 1976). The mean square error of the measurements in 1974 was $\pm 1.3 \mathrm{nT}$, in $1975 \pm 1.8 \mathrm{nT}$, and in 1976$1977 \pm 0.5 \mathrm{nT}$. Changes of the field on the routes for 1974-1975, 1974-1976, 19761977 are presented in Fig. 3. 
As is seen from the diagrams, the greatest changes of the field were observed in 1974-1975 and 1975-1976. The smallest changes of the field were observed in 1976-1977. This is most clearly seen in the histograms of field variations. Histograms showed least variation in 1974-1975 and 1974-1976 (Fig. 4a, b) and most

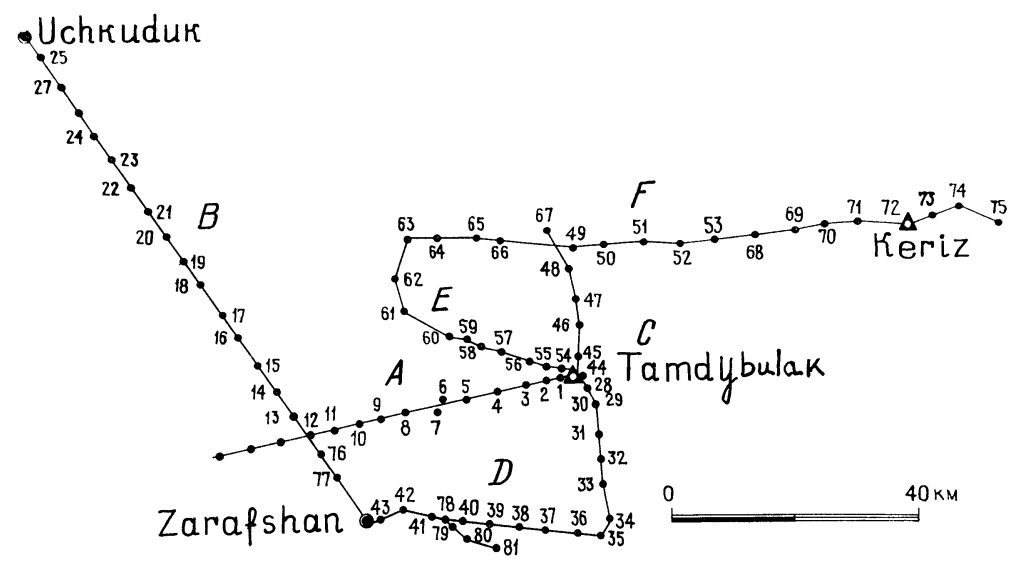

Fig. 2. Sketch map of Kyzyl-Kum geomagnetic polygon. Dots and digits symbolize the survey points; triangles, point of reference. A, B, C, D, E, F: survey profiles.
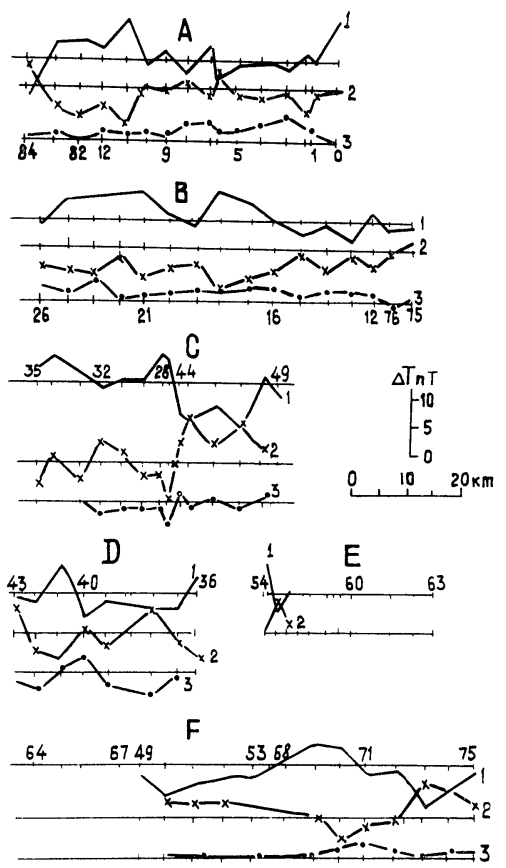

(a)
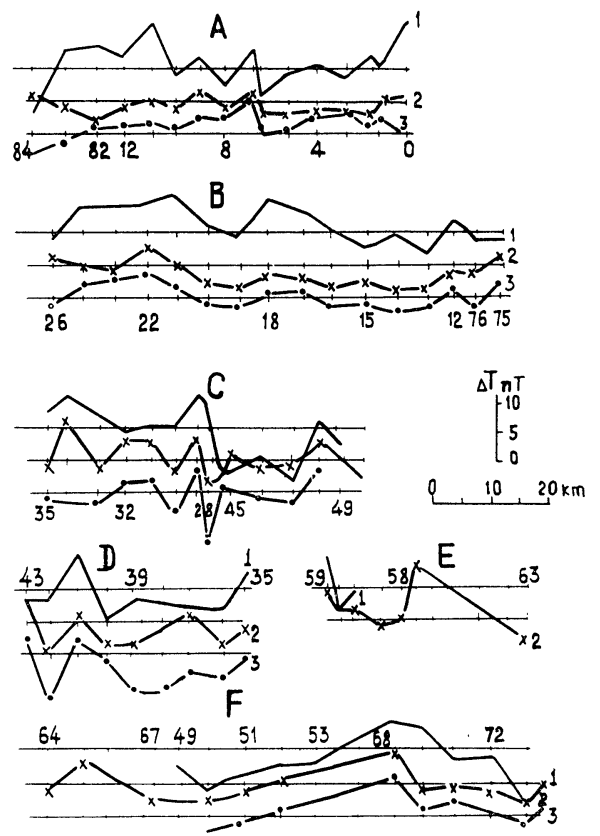

(b)

Fig. 3. Changes of the geomagnetic field $T$ along the profiles of Kyzyl-Kum polygon. (a) 1, $\Delta T$ difference (1974-1975); 2, $\Delta T$ difference (1974-1976); 3, $\Delta T$ difference (1974-1977). (b) 1, $\Delta T$ difference (1974-1975); 2, $\Delta T$ difference (1975-1976); 3, $\Delta T$ difference (1976-1977). A, B, C, D, E, F: survey profiles (Fig. 2). 


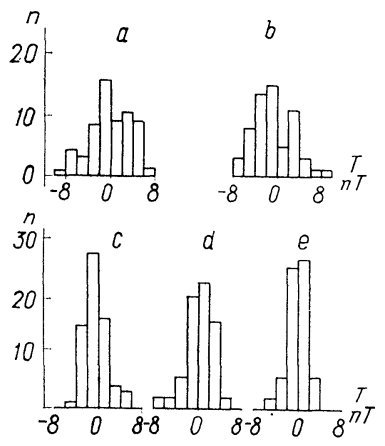

Fig. 4. Histograms for total force $T$ distributions during 1974 1975 (a), 1975-1976 (b), 1974-1976 (c), 1974-1977(d), 1976-1977 (e). $n$ : number of points.

variation in 1976-1977 (Fig. 4c, d, e). This suggests to us that the changes of the field in that polygon in 1975 were probably anomalous. Observations of 1975 were made 5-6 months before the earthquakes of the 8th of April and 17th of May, 1976 in Gazly with the magnitude $M=7-7.5$. The next observations were made in October 1976. Probably the whole territory of the polygon was in a stressed state before the earthquakes. According to the modern opinion the region of elastic stress accumulation occupies much more territory than was considered earlier. Thus before the Gazly earthquakes, the region of stress accumulation with the deformation value $10^{-7}$ may have occupied territory with a radius of $650-700 \mathrm{~km}$.

The points of Kyzyl-Kum polygon were at distances of $180-250 \mathrm{~km}$ from the epicenter of the Gazly earthquakes. Therefore the territory of the polygon could exist in a stressed state. The distribution of fracturing which had taken place favors this view. In 1974-1975 intensive processes of fracturing were seen at some sections of the polygon. After the earthquake these processes sharply decreased. Probably, the Gazly earthquakes and fracturings were caused by the same source.

Our statement is still an assumption, and not a proven fact. However, we can add that the average square error had its greatest value $\pm 1.8 \mathrm{nT}$ in the anomalous (1975) year. Also supporting this supposition is the fact that the maximal change of the field $8 \mathrm{nT}$, discovered at the point of reference of Tamdybulak is in the region of fracturing. This change was seen in 10-day averages (one reading every $10 \mathrm{~min}$ ) in 1974-1975. Total field variations in Tamdybulak were compared with those of the magnetic observatories Yangi-Bazar, Vannovskaya, and Novokazalinsk.

\section{Fergana Polygon}

Measurements at Fergana polygon were made for $1972-1973$ by the closed route with a total length of $650 \mathrm{~km}$ (Fig. 5). The routes passed through seismically active zones, enveloping abyssal fractures, epicenters of strong earthquakes, gradients of modern and the recent motions of the earth's crust and gradients of geophysical fields. Until 1975 the Yangi-Bazar observatory was used as a point of reference for the Fergana polygon. The distance between the observatory and the southeastern part of the polygon is $350 \mathrm{~km}$. The average square accuracy of the measurements 

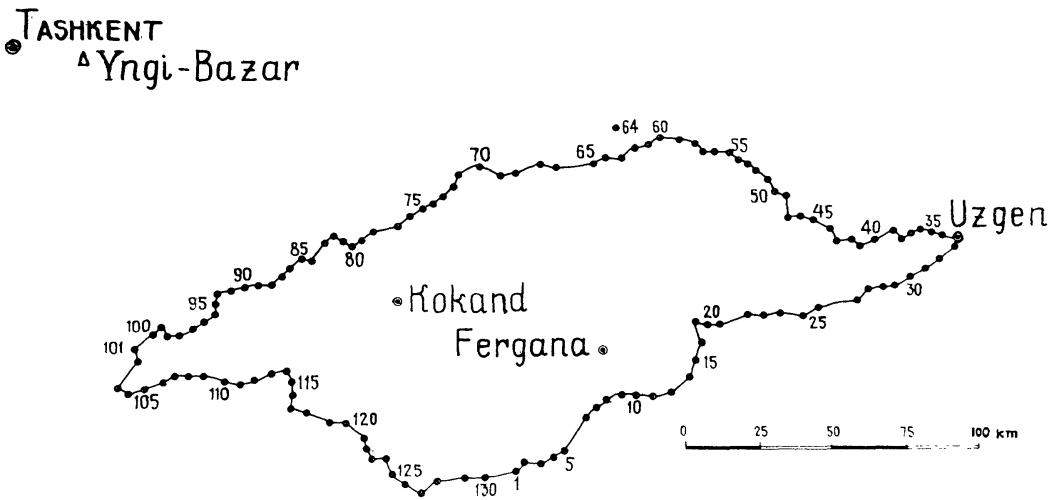

Fig. 5. Sketch map of Fergana geomagnetic polygon. Dots and digits symbolize survey points.

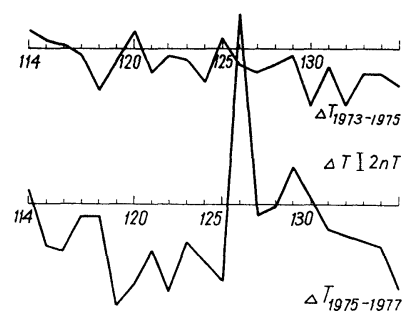

Fig. 6. Changes of the geomagnetic field total force $T$ along the profile Kanibadam-Vuadil (points 114-135).

at that polygon was $\pm 3-4 \mathrm{n} T$ in 1975 . Measurement errors because of incorrect calculation of the variations at separate points could be as large as $10 \mathrm{nT}$. In that connection the results of the measurements of 1975 are not discussed in detail. In 1975 after using a synchronous method of measurement with the magnetometer T-MII (MAKsimovskikH and SHAPIRo, 1976) the average square error of measurements decreased significantly.

Changes of the field in the route Kanibadam-Vuadil (points $114-130$ and 1-15) appear to be anomalous. Here, in the direct neighborhood of the route $(5-6 \mathrm{~km}$ to the northeast) a strong earthquake with a magnitude $M=5.75$ took place on the 31 st of January, 1977. The depth of the hypocenter was about $15 \mathrm{~km}$. Changes of the field at the route for 1973-1975 and 1975-1977 are presented in Fig. 6. Unfortunately, the latest investigations before the earthquake were made in that part of the route in 1975 . The repeated measurements were made 10 days after the earthquake. Large field changes in 1973-1975 were not observed. In the period 1975-1977 we can observe, in the area of the 125 th point, sharp changes of the field. The maximum change along the route reached $29 \mathrm{nT}$. Besides that, changes of the field level between points $114-125,125-130$ and $1-5$ are marked. The average change is about $15 \mathrm{nT}$. Probably, the observed anomalous variations of the geomagnetic field are due to the redistribution of elastic stresses after the strong earthquake. We suggest that the position of the maximum change indicates the zone of maximum stressing associated with the epicenter of the earthquake. It is worth remarking that the epi- 
center of the next strong earthquake with the $M=5.5$ of the 3 rd of June, 1977 shifted in that direction to a distance of $30-40 \mathrm{~km}$.

\section{Water Reservoir of Charvak}

Geomagnetic field variations were observed in detail in a region in which a water reservoir was being filled. A network of points was located in 1973 around the water reservoir of Charvak. The distance between the observation points was $1-2 \mathrm{~km}$ and they were removed from the water reservoir bank by some hundred meters of up to $10 \mathrm{~km}$. The measurements were repeated once every $1.5-2$ months for winter months and 1-2 times a month in other periods of the year. Yangi-Bazar observatory was used as the point of reference. The distance between the observatory and the field points is $50-60 \mathrm{~km}$. Anomalous variations of the field at the majority of the points were correlated with the change of the water level in the reservoir. Maximum changes in separate points were as high as 15-25 nT. At points near to the reservoir, the intensity of the changes was greater. Average changes of the field at 35 points for $1974-1976$ is presented in Fig. 7. The value of the average change achieves $10 \mathrm{nT}$ in 1975-1976. The intensity of the $T$ anomaly depends on the volume of water - the greater quantity of the water in the reservoir, the greater was the amplitude of the variations. In spite of the obvious linkage between the geomagnetic field changes and the water reservoir filling, the nature of these anomaly variations cannot be explained simply, for the observed anomalies could not be caused by excessive pressure only, which rises on filling, but by anomalous electroconductivity, appearing while moistening the soil around the water reservoir. Further research will evidently allow us to speak more definitely about the nature of such anomalous variations of the geomagnetic field.

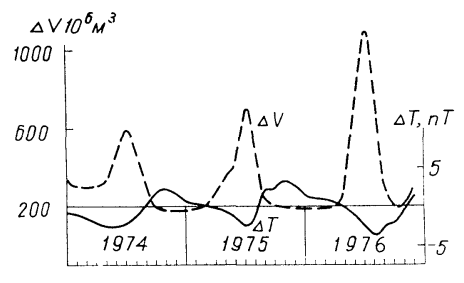

Fig. 7. Variations of the geomagnetic field total force $T$ as a result of the changes of water volume in Charvak reservoir.

\section{Conclusions}

Having analyzed the results of the geomagnetic variation in geodynamical polygons situated in seismoactive regions of the Middle Asia, we conclude:

1) In all the polygons-namely, Tashkent, Kyzyl-Kum, Fergana-we have observed anomalous variations of geomagnetic field total force $T$ with magnitudes up to $25 \mathrm{nT}$. In some cases such variations appear to be correlated with earthquakes.

2) At all the enumerated polygons the degree of anomalous behavior of the secular variation field was qualitatively correlated to the seismic activity. 
3) At Kyzyl-Kum polygon the process of active fracturing terminates after the strong earthquakes of the 8th of April and 17th of May, 1976.

4) At the water reservoir of Charvak distinct correlation of an anomalous variation of the field with the level of reservoir filling has been observed.

The present results indicate that on the basis of the geomagnetic research at the geodynamical polygons, widening of the area of observation and improvement of the observation procedure will enable us to understand fully the tectonomagnetic processes in this area.

\section{REFERENCES}

Abdullabekov, K.N. and S.Kh. Maksudov, Geomagnetic Field Variations in Seismoactive Regions, pp. 34-55, FAN Publishers, Tashkent, 1975.

Maksimovskikh, S.J. and V.A. Shapiro, Portable proton precession magnetometer of high accuracy T-MII, Geomagnetism y Aeronomia, XVI, 389-391, 1976. 